\title{
RUMOS E RUMORES
}

Vera Follain de Figueiredo

Ao viajar até o país dos Tarahumaras, Artaud não o fez para entrar num mundo novo, mas para sair de um mundo falso.

Silviano Santiago

O conto $O$ caminho de Santiago, de Alejo Carpentier, ambientado na Europa do século XVI, tem como personagem principal um tal Juan, jovem espanhol que não resiste à tentação de correr mundo como "tanbor de tropa". A idéia de viajar, marcando o ritmo da marcha dos soldados, lhe parece mais atraente do que ficar em sua aldeia e seguir a vida religiosa. No cntanto, em suas andanças, acaba por contrair a peste e,com medo de morrer, faz a promessa de percorrer o caminho de Santiago, como peregrino, caso lhe fosse concedido o milagre da cura. Vai, então, Juan, convalescente, vestido com o hábito de peregrino, pisando o chão de Paris, sem pisar o chão das tavernas, em direção a Santiago de Compostela. À medida que o vigor físico se restabelece, continua a viagem, mas já não evita os vinhos. Atirado de surpresa a uma feira, conhece Juan Indiano, que se apresentava com um mico no ombro e um papagaio na mão e vendia, dentre outras coisas, dois jacarés empalhados, afirmando que os trouxera de Cuzco. O viajante fala das maravilhas das Índias Ocidentais e Juan Romeiro se deixa encantar pela narrativa dos prodígios que o outro conhecera:

Esquentado pelo vinho, o indiano começa a falar dos prodigios menos divulgados: de uma fonte de águas milagrosas, nas quais os velhos mais curvados e entrevados mergulhavam e logo saiam com a cabeça coberta de cabelos lustrosos, as rugas alisadas, a saúde recuperada, os ossos desentorpecidos e tesão suficiente para emprenhar um exército de amazonas. [...] Havia também uma cidade, irmã de Jauja, onde tudo era de ouro - até as bacias dos

Vera Follain de Figueiredo é professora na UERJ. 
barbeiros, as caçarolas e os tachos, o aro das rodas das carroças e as lamparinas. (1995, p.27-28)

Seduzido pelo discurso de Juan Indiano, Juan Romeiro larga o hábito de peregrino e embarca para as terras americanas, onde não encontra ouro, nem sereias, nem fontes de juventude. Encontra violência, intriga, competição, num povoado recém-fundado, no qual a ambição acirra a maldade. Rejeita os costumes diferentes, a falta de vinhos, a natureza inclemente. Ao conseguir voltar para a Europa, Juan, agora denominando-se Juan Indiano, se apresenta nas feiras narrando as maravilhas das Índias Ocidentais e convence um tal Juan Romeiro que se encaminhava para Santiago de Compostela a embarcar num navio em Sevilha, rumo a Manoa, onde haveria mais ouro do que as tropas eram capazes de trazer da Nova Espanha.

O conto de Carpentier sintetiza a atmosfera da Europa no período de transição da Idade Média para a Idade Moderna. A religiosidade medieval em ruinas, a miséria, as doenças, a dissolução dos valores da sociedade feudal teocrática, a crescente repressão exercida pela Igreja católica, empenhada em manter o seu domínio, a mistura de raças, culturas e credos no solo europeu, como conseqüência da atividade comercial, das guerras e das peregrinações religiosas. Encena, sobretudo, o fascínio das viagens, ou melhor, o fascínio exercido pelas narrativas de viagem, verdadeiras ou imaginárias. Juan Indiano é a outra face de Juan Romeiro, a face que aponta para o desgaste do maravilhoso cristão, disciplinado, regulamentado no milagre, e para a força crescente do maravilhoso propriamente dito, que não se restringe ao arbítrio de um só Deus, contando com inumeráveis forças sobrenaturais e com a sedução do imprevisível. O que mais caracterizou aquele momento, entretanto, foi a tensão que se estabeleceu entre esses dois tipos de narrativa: a que tem a Biblia como referência para tudo e a que desliza para um universo povoado de monstros, seres estranhos, ilhas de pérolas, montanhas de ouro: fenômenos não catalogados nos textos cristãos. As figuras do peregrino e do viajante se sobrepõem, se trocam, como acontcce com Juan Romeiro e Juan Indiano: é o homem dividido entre os referenciais do passado e o apelo do novo. Quando prevalece o espírito do peregrino, a significação da viagem não ultrapassa a identidade do mesmo:

O peregrino perseguia aquilo que ele já sabia, a confirmação absolutória de um Absoluto desde sempre creditado, ele nunca se desprendia das fronteiras de uma verdade que se exauria em exi- 
gir a sua própria confirmação, ainda que, e mesmo principalmente, através de milagreiras penas sequiosas de redenção. Os tortuosos caminhos ratificavam a identidade do principio e do fim: do mesmo se ia ao mesmo, e tudo isso mais nada tinha a ver com o mundo. (Bornheim, 1998, p.32)

Quando prevalece o impulso para a grande viagem, fala mais alto a aventura de se lançar ao desconhecido, de conferir os prodígios que povoam as narrativas, ainda que, muitas vezes, o impacto causado pelo novo leve o viajante a tentar enquadrá-lo nos parâmetros do já conhecido. Seja como for, viajante e peregrino são frutos da mesma insatisfação, e cada qual, a seu jeito, busca uma saida para os males que assolam o contexto europeu da época. Daí por que Erasmo, no Elogio da loucura, escrito em 1509, considera tanto um como outro insanos. Para ele, são loucos os viajantes que, por um lucro magro e duvidoso, correm através dos mares e dos ventos colocando em risco uma existência que dinheiro nenhum poderia restituir. Mas também são loucos os peregrinos que largam "a casa, mulher e filhos para ir a Jerusalém, a Roma, ou então a Santiago onde nada os chama" (Rotterdam, 1997, p.60).

Erasmo olha o mundo com distância e ironia, a partir da certeza de que a única verdade está na sabedoria divina e de que a única busca válida é a busca interior, voltada para o encontro com Deus. Seu livro é um longo monólogo no qual a loucura, diante de um auditório repleto, faz o elogio de si mesma. A loucura a que o autor se refere é aquela que contamina a razão, que se encontra no âmago da própria razão, disseminando-se de tal forma que ninguém dela escapa, nem os sábios, nem o clero, nem Cristo, já que ele se revestiu da natureza humana. Torna-se, assim, impossível traçar limites entre sanidade e insanidade. A loucura subjaz a tudo que é humano, é incrente ao homem, à sua presunção, à sua vaidade.

A dissolução dos limites entre loucura e razão está em consonância com um mundo que se encontra no limiar entre os valores medievais já em decadência e os valores modernos em gestação. Não é, portanto, à toa que o imaginário do período vai estar marcado pela presença da loucura e que, como nos fala Bakhtin, folguedos, como a "festa dos loucos", celebrada nas ruas e tavernas, ganham tamanha importância que acabam por ser proibidos nos fins da Idade Média. Por outro lado, Foucault nos chama a atenção para a associação entre o mar e a loucura, manifesta na existência do estranho hábito, cultivado no século XV, de se escorraçar os loucos das cidades, confiando-os aos marinheiros, mercadores e peregrinos. Assim surgem as chamadas "naus dos loucos", navios que car- 
regavam insanos em busca da razão. $O$ autor chama a atenção para o caráter simbólico desse hábito:

Esta navegação do louco é simultaneamente a divisão rigorosa e a Passagem absoluta. Num certo sentido, ela não faz mais que desenvolver, ao longo de uma geografia semi-real, semi-imaginária, a situação liminar do louco no horizonte das preocupações do homem medieval situação simbólica e realizada ao mesmo tempo pelo privilégio que se dá ao louco de ser fechado às portas da cidade: sua exclusão deve encerrá-lo; se ele não pode e não deve ter outra prisão que o próprio limiar, seguram-no no lugar de passagem. (Foucault, 1991, p. 12)

É também a partir de uma geografia semi-real e semi-imaginária que, no final desse mesmo século, os homens vão se lançar ao mar para empreender as grandes navegações. Vão se lançar ao desconhecido, "ao mar de mil caminhos, a essa grande incerteza exterior a tudo", para usar as mesmas expressões de que Foucault lança mão ao descrever a viagem das naus dos insensatos. Mas ao contrário dos loucos, cuja "única pátria é a extensão estéril entre duas terras que não the pertencem" $\mathrm{e}$ que, por isso, não têm para onde regressar, a viagem do navegante só se realiza plenamente se houver o regresso que dá notícia da viagem, ou seja, a aventura náutica é tributária da experiência do relato. A nau dos loucos era o barco sem origem e sem fim. Era o barco da viagem sem volta e, portanto, silenciosa. A nau dos navegantes é o navio daquela loucura que organiza seu próprio discurso sedutor, como no livro de Erasmo. A loucura constrói seu discurso e com ele atua sobre o real: o relato do louco viajante alimenta as novas viagens. As palavras, situadas na fronteira entre o real e o imaginário, seduzem o ouvinte. Buscam dar sentido à experiência, e o choque diante da diferença, da absoluta novidade, suspende as fronteiras entre o fantástico e a realidade. O ser fantástico mostra que o real atual é ordem relativa. Assim, as representações fantásticas das Terras Desconbecidas, propostas na Idade Média, estimularam o espírito de descobrimento das grandes navegações:

Honório d'Autun descreveu no século XII, no De imagine mundi, Ciópodes que caminham com um só pé e homens sem cabeça ou que se alimentam do mero aroma de uma fruta. Pierre d'Ailly (1350-1420), cuja Imago mundi foi lida e anotada por Colombo, afirmava a existência dos cinocéfalos, homens com cabeça de cachorro; Colombo supôs ter dado com o rasto deles em sua primeiraviagem. (Lacroix, 1996, p.65) 
Nesse sentido, Colombo, guiado e cego por suas crenças, é Juan Romeiro, quando, obcecado pela idéia de encontrar o Paraíso Terrestre, assume-se como profeta do fim dos tempos. Interpreta o seu deslocamento no espaço como um deslocamento no tempo e sobrepõe à cartografia real, uma cartografia imaginária, imprimindo sentido e direção ao vagar incerto pelos mares. Ele chegou a acreditar que caminhara em direção à origem, ao passado adâmico, que, uma vez atingidos, indicariam a iminência do fim do mundo. Conhecer a totalidade do Universo implicava o fechamento do espaço e do horizonte temporal, numa perspectiva escatológica. Mas Colombo é, também, Juan Indiano, no momento em que se lança numa aventura, quando não consegue se furtar de todo à percepção do novo, e, sobretudo, quando narra, para os reis, os prodígios, as riquezas das terras encontradas e os seduz com suas palavtas, convencendo-os a patrocinar outra viagem.

As viagens de descoberta vão servir de inspiração para Thomas More, que, em 1516, escreve o livro que chamou de Utopia. A utopia de More não é o Paraíso Terrestre buscado por Colombo, não pressupõe a volta às origens, mas considera o futuro, o mundo que o homem pode vir a construir. $O$ espaço a ser descoberto é agora um lugar ideal, construído pelo discurso e no discurso, que aponta para a Terra que, através da sua ação, os homens tornarão nova. A grande viagem se realiza no espaço literário, território de onde a vontade do homem, dirigida pela razão, vai poder olhar criticamente o Velho Mundo. A utopia é a consagração do pensamento da diferença em relação ao que existe: o imaginário já não é o dos monstros nem prodígios. Produto confesso da escrita, a utopia se quer verossímil: ć o imaginário a serviço da razão crítica, numa visão que já é moderna e que estará na base de grande parte das narrativas de viagem dos séculos seguintes, como, por exemplo, nos relatos poéticos de Artaud sobre sua viagem ao México, nos quais se percebe a procura utópica de um contraponto para a civilização ocidental, considerada por ele mediocre e decadente.

Chegando ao final do século $\mathrm{XX}$, a cerca de quinhentos anos do início da Era Moderna, realizado sob o signo das viagens, nos ocorre perguntar sobre o lugar que elas ocupam no imaginário contemporâneo. Que significa, hoje, viajar? Qual o lugar de onde se relata a viagem? $O$ da razão que organiza a experiência, segundo um fim na história? $O$ da loucura que denuncia a falácia da ordenação causalista e teleológica? O da fé que despreza esses dois lugares mencionados em nome da ordem divina? Que outro Juan tomou o lugar de Juan Romeiro e Juan Indiano? Há espaço para uma narrativa de viagem orientada pela utopia de um mundo melhor? 
Quer nos parecer que, pelo menos numa certa literatura, a figura que surge é de um Juan errante, que perdeu os referenciais de origem e destino e cujo relato contamina-sc da falta de direção da trajetória do narrador. No imenso espaço conhecido do mundo, o errante se desloca, mas não viaja, no sentido moderno da palavra. A temporalidade vazia em que se move não aponta senão para o presente, no qual o diferente não é surpresa nem promessa, é exótico. Espaço e tempo, categorias indissociáveis, ficam vazios quando o próprio caminho da história perde o sentido e o sagrado já não aponta para um além, estimulador do imaginário, voltando-se para a vida imediata. $O$ errante vaga por um mundo que perdeu todo e qualquer mistério. Como observa Georges Balandier (1997), nada parece escapar à apropriação científica do mundo, das coisas, dos seres, a um cadastramento minucioso do real, que introduz uma visão instrumental, difundindo uma representação contábil da vida.

Num mundo que se quer mais e mais transparente e programável, o encantamento da narrativa de viagem tende a se quebrar: há pouco ou quase nada para contar e ninguém para ouvir. O lugar de onde se fala é qualquer um, por isso não se opõe a um outro lugar. Em Hotel Atlâtico, de João Gilberto Noll, o personagem errante vaga de um espaço para outro sem rumo, pousa num hotel, local de passagem, que não remete para nenhuma raiz e morre diante de um mar que já não sugere nada, cuja imensidão não tem segredos - é o vazio. Não existe a tensão entre uma cartografia real e uma cartografia imaginária, porque, simplesmente, o errante dispensa qualquer mapa - ele perambula pelos lugares a esmo. Não há uma seta do tempo apontando alguma direção: nem para o paraíso, nem para a utopia. Como vemos, por exemplo, no romance Teatro, de Bernardo Carvalho, o narrador, hoje, torna-se um nômade, porque sua identidade se dissolve, se transmuda: trata-se de um ator que encena a vida na superficie. Sem possibilidade de um ponto fixo, de onde se organizem os eventos, a narrativa de viagem também fica à deriva - não há um porto seguro que lhe sirva de referencia constante.

A Terra, tornada acessível em todas as regiões, banaliza as viagens, porque já não há espaços inexplorados, e viajar é mais reconhecer do que descobrir. Compra-se um pacote com o tipo de viagem que se deseja fazer, para viver, temporariamente, de maneira segura, a experiência da diferença. Esta é a situação vivida pelo casal rico que resolve fazer um turismo selvagem na lua-de-mel, no conto Viajem de núpcias, de Rubem Fonseca. Considerando que, como dizia o professor de filosofia da personagem, "as cidades do mundo são concêntricas, isomórficas, sincrônicas", e que "só uma existe e você está sempre na mesma", os recém- 
casados escolhem descer as corredeiras do "remoto, selvagem e poderoso" rio Colorado, que atravessa "a dramática e fascinante" rocha de trezentos metros de altura - tal como anunciado no folheto turístico. $O$ folheto, entretanto, indo contra todo o espirito de aventura, também informa que: "toda balsa tem um toalete especial, que é diariamente esvaziado num depósito anti-séptico da balsa e depois levado para a sede da empresa de turismo", sendo "proibido urinar ou fazer qualquer coisa no terreno, o solo e cada pedaço de pedra são preservados e protegidos por lei"'. (Fonseca, 1997, p.42)

Essa mesma tendência para a fuga programada do cotidiano faz surgir, sobretudo no cinema, um outro tipo de narrativa, que vai explorar o imaginário cósmico - ciência e técnica permitem ao homem escapar, pela imaginação, do velho espaço terrestre e se lançar com suas naves rumo a outras galáxias. Juan Indiano se transforma, então, em Juan Humanóide. Ou, em Juan Internauta, se prefere dedicar-se à navegação virtual, conquistando uma sobre-realidade, confortavelmente instalado em sua casa. De qualquer forma, as viagens continuam, em alguma dimensão, estimulando o imaginário, mesmo que a utopia tenha sido exilada em outro planeta.

Por outro lado, Juan Indiano, agora, já não precisa apresentar-se na feira com um papagaio e um mico nos ombros, apregoando as maravilhas das Índias Ocidentais. Tornou-se publicitário e apregoa, na TV, as maravilhas do consumo, nos impelindo a participar da "viagem" a esse mundo de prodígios, onde uma simples margarina é capaz de garantir a felicidade familiar. Nesse sentido, o filme Ladrões de sabonete (1989), de Nanni Moretti, ilustra, através de suas personagens que abandonam as agruras do neo-realismo e emigram para o espaço de sonho dos anúncios, a viagem pós-moderna por excelência. Na mesma dimensão, cabe lembrar que Juan Romeiro, seduzido pelo encantamento desse outro mundo, também já não precisa mudar de nome nem tirar o hábito: é televisado cantando rock nas igrejas.

\section{REFERÊNCIAS BHBLIOGRÁFICAS}

CARPENTIER, Alejo, Guerra do tempo. Rio de Janeiro: Bertrand Brasil, 1995 , p. 27-28. Tradução de Mário Pontes.

BORNHEIM, Gerd. A descoberta do homem e do mundo. Novaes, Adauto (org.). A descoberta do homem e do mundo. São Paulo: Companhia das Letras, 1998.

ROTTERDAM, Erasmo. Elogio da loucura. São Paulo: Martins Fontes, 1997, 2.ed. Tradução de Maria Arminda Galvão G Pereira. 
FOUCAULT, Michel. História da loucura. São Paulo: Perspectiva, 1991, 3.ed. Tradução de José Teixcira Coelho Neto.

LACROIX, Jean-Yves. A utopia. Rio de Janeiro: Jorge Zahar, 1996. Trad. Marcus Penchel.

BALANDIER, Gcorges. O contorno: poder e modernidade. Rio de Janeiro: Bertrand Brasil, 1997. Tradução de Susana Martins.

FONSECA, Rubem. Histórias de amor. São Paulo: Companhia das Letras, 1997. 